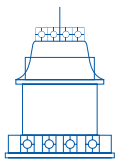

ARTÍCULOS

DE REFLEXIÓN

\title{
¿Existencia auténtica en la época de la técnica?
}

\author{
Claudia Marcela Gómez Herrera \\ Universidad Nacional de Colombia, Bogotá, Colombia \\ E-mail: claudiamgomez2@gmail.com
}

Recibido: 31 de mayo de 2019 | Aprobado: 10 de noviembre de 2019

https://doi.org/10.17533/udea.ef.n61a11

Resumen: En sus escritos tempranos Heidegger plantea que la existencia fluctúa entre un modo de ser auténtico e inauténtico. Una de las diferencias que se establece entre estos modos de la existencia consiste en la manera en la que se experimenta el tiempo en uno y otro. El presente artículo pretende proponer un enlace entre las nociones de temporalidad heideggeriana y, a la luz de dicho enlace, establecer los rasgos que la existencia auténtica podría adquirir en la época de la técnica. Para lograr este propósito, retomaré una cita de Borges con el fin de esbozar cómo podría pensarse una relación entre las dos nociones de temporalidad. Una vez esbozada la relación, se revisarán algunas de las tesis heideggerianas sobre la época de la técnica que nos ofrezcan las herramientas para reflexionar acerca de los matices que adopta la existencia auténtica en nuestra época. En ese sentido, sugiero que la serenidad puede concebirse como la manera en la que la existencia auténtica actúa. La serenidad no es pasividad del hombre frente a la técnica, sino un modo de responder al acontecer del ser, una manera genuina de actuar acorde a la época.

Palabras clave: temporalidad originaria, Ereignis, existencia auténtica, existencia inauténtica, destino, técnica, época de la técnica, serenidad

* El presente artículo se deriva de una investigación doctoral en curso intitulada Tiempo y Existencia: Una lectura de la Kehre a la luz de la temporalidad del Dasein.

Cómo citar este artículo:

Gómez Herrera, C. M. (2020). ¿Existencia auténtica en la época de la técnica? Estudios de Filosofía, 61, 167-185. https://doi.org/10.17533/udea.ef.n61a11

\section{OPEN ACCESS}




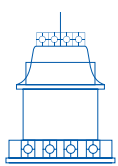

ARTÍCULOS

DE REFLEXIÓN

\title{
Authentic existence in the age of technique?
}

\begin{abstract}
In his early writings, Heidegger argues that existence fluctuates between an authentic and an inauthentic mode of being. One of the differences of these modes of existence is the way in which time is experienced in each other. This paper aims to propose a link between these notions of temporality and, in the light of that link, to determine the main features of the authentic mode of being in the age of technique. To achieve this goal, I analyze a quote from Borges in order to sketch out how we can think a relationship between the two notions of temporality. Once the relationship has been sketched, I will review some of Heidegger's theses on the epoch of technique that offer us the tools to reflect on the nuances that authentic existence adopts in our epoch. This article aims to think on how a relationship between the two notions of temporality could be considered and, considering this link, the features that the authentic existence could acquire in the age of technique. In that sense, I suggest that serenity can be conceived as the way in which authentic existence acts. Serenity is not the passivity of man versus technique, but a way of responding to the occurrence of being, a genuine way of acting according to the time.
\end{abstract}

Key words: original temporality, Ereignis, authentic existence, inauthentic existence, technique, age of technique, serenity

\section{Claudia Marcela Gómez Herrera}

Estudió filosofía en la Universidad Libre de Colombia donde fue becaria y se graduó con mención meritoria en el año 2009. Realizó estudios de Maestría en filosofía en la Universidad Nacional de Colombia y se graduó en 2016; actualmente se encuentra adelantando estudios de Doctorado en la misma universidad. Realizó distintos cursos en el Instituto Caro y Cuervo, como latín, griego, diplomado en Literatura y Cultura y Taller de escritura y corrección de estilo. Ejerció como docente entre los años 2009-2016 para la Universidad Francisco de Paula Santander (CREAD, modalidad semi-presencial). Publicó los artículos: De la amistad a la política y a una política de la amistad (2012) y Pasión tiránica por el lenguaje (2007) en la Revista Colombiana de Filosofía Sin Fundamento. 


\section{Introducción}

Formular una pregunta no es solo erigir y proferir una oración interrogativa para expresar una duda o para enfatizar determinados puntos de un discurso. La persona que realiza una pregunta se implica a sí mismo en ella, para formularla parte de sus intereses, de las posibilidades de sentido configuradas por la época y por la cultura -el contextoen la que vive, y de la comprensión que posee de un asunto (o del horizonte que rodea dicho asunto). Al ponerse a sí mismo en la pregunta el interrogador, además, abre un camino ${ }^{1}$ que direcciona el modo en el que ella se ataca, pues él (el interrogador) elige formularla de un modo determinado, se adhiere a una manera específica de comprender un fenómeno y anticipa de algún modo el recorrido que puede adquirir el discurso. Las características del preguntar enunciadas aquí solo a groso modo se acentúan en el preguntar filosófico. En Conceptos fundamentales de la metafísica. Mundo, Soledad y finitud (en adelante: CFM), Heidegger distingue el preguntar característico de la filosofía como uno en el que "el ser-ahí en el hombre dirige en el filosofar el ataque contra el hombre" (Heidegger, 2007b, p. 46; GA 29/30 p. 30). A pesar de los términos empleados por Heidegger, la definición no posee una connotación negativa, sino que ellos se emplean para enfatizar en la manera cómo el filósofo está siempre co-implicado en la pregunta. Esta co-implicación -así como en el preguntar en general- refiere a los intereses, la época y la cultura a la que pertenece el filósofo, pero también señala que el "objeto" de la pregunta en el caso de la filosofía es el filósofo mismo, él se ataca a sí mismo (como hombre); cuando se pregunta v.gr. por el mundo, la animalidad, el ser, el tiempo, etc., el hombre (filósofo) se pregunta a sí mismo por sí mismo, por la relación que determinado fenómeno posee con él.

Iniciar un artículo que reflexiona acerca de Heidegger en el siglo XXI retomando algunos elementos constitutivos del preguntar se debe a que el tema funciona aquí a modo de pregunta, es decir, abre el camino a seguir: instaurar un diálogo con la filosofía heideggeriana y estar prestos a escuchar los aportes que ella puede realizar a la filosofía del siglo XXI, ya sea en un debate con autores contemporáneos o atendiendo a aquello que puede decir sobre nuestra época. Aquí me concentraré en la segunda bifurcación del camino, es decir, retomaré la filosofía heideggeriana atendiendo a las reflexiones que de ella pueden derivarse acerca de la denominada época de la técnica.

El diagnóstico que realiza Heidegger de nuestra época denuncia que en ella prolifera la convicción de que el hombre domina lo ente por medio de la técnica moderna, mientras pasa desapercibido para él el hecho de que nos acecha el peligro de ser nosotros mismos dominados, e incluso, de llegar a convertirnos en un engranaje de

1 Gadamer al exponer la dialéctica de pregunta y respuesta distingue a la pregunta como un método. La etimología del término método deriva de metha (más allá) y odos (camino o vía para llegar más lejos, o encaminarse a un fín). Gadamer al exponer la dialéctica de pregunta y respuesta otorga un lugar privilegiado a la idea de que el diálogo es un camino que no es impuesto por los interlocutores, sino que se abre en la conversación conduciéndola (Cf. Gadamer, 2007, p. 439). 
la maquinaria técnica. Pero el panorama de la época de la técnica no es totalmente oscuro, el hombre está ubicado justo en la frontera entre la historia del olvido del ser y la superación del pensamiento metafísico en la que el hombre podría estar atento y corresponder genuinamente al acontecimiento apropiador (Ereignis).

Sin embargo, el problema que ocupa a Heidegger, como es bien sabido, no es exactamente la época de la técnica, sino la inherencia entre ser y tiempo. ${ }^{2}$ En textos tempranos el problema fue abordado a partir de un análisis ontológico del hombre ${ }^{3}$ que poco a poco se fue relegando a un segundo plano. ${ }^{4}$ Tras la Kehre, el giro del pensamiento heideggeriano, la tarea era mostrar que el ser es temporal en sí mismo y no porque derive de la temporalidad del hombre, tarea en la que el preguntar por el emerger del sentido incluía revelar cómo él se instaura en las distintas épocas históricas, épocas que hasta la actual, están determinadas por el pensar metafísico.

Con la Kehre, algunas de las nociones que plantea el joven Heidegger se pierden o resignifican. Las nociones de existencia auténtica e inauténtica, ${ }^{5}$ que nos ocupan en el presente texto, se desvanecen en muchos de los textos tardíos, y aunque dichas nociones se vuelven a perfilar, será otorgándoles un sentido distinto. En la terminología de Ser y tiempo (1997; en adelante: ST), autenticidad e inautenticidad son términos que designan modos de ser ${ }^{6}$ en los que oscila la existencia. Para decirlo brevemente, en la cotidianidad la existencia se mantiene primariamente en la inautenticidad; el hombre generalmente no elige entre las posibilidades que se le presentan, sino que más bien sigue o sucumbe irreflexiva y ciegamente a los sentidos o las significaciones que se han instaurado socialmente (opiniones comunes), ellas prescriben y regulan nuestra

2 El problema que invade la filosofía heideggeriana es la co-pertenencia entre ser y tiempo. Desde la mitad de la década de los 20s (1924) la pregunta que Heidegger se planteaba era por el sentido del ser, a inicios de los años 30 por la verdad del ser, desde 1936 por el Ereignis y finalmente a inicios de los años 70 por el Eignis (propiación). Sin embargo, los tres últimos "nombres" que adquiere el problema corresponden a momentos en los que se trabaja la noción de Ereignis, de acontecimiento apropiador —en el periodo de la verdad del ser en ciernes-, noción que constituye uno de los hilos distintivos de los textos de madurez. La pregunta por la co-pertenencia, brevemente, puede pensarse como la pregunta por la comprensión del ser (sentido) desde la dimensión del presente (tiempo). Cf. Dastur (1999, p. xxiii).

3 Empleo aquí hombre en lugar de Dasein, en virtud de la resignificación que adquiere este término en los textos tardíos. Sin embargo, utilizo Dasein en algunos momentos para evitar la redundancia en el texto.

4 El énfasis que le dio Heidegger al análisis ontológico del Dasein llevó a que se interpretara que, en tanto el sentido del ser del hombre es la temporalidad, el hombre — gracias al problema de la co-pertenencia entre ser y tiempo— da o instaura ser y tiempo. Sin embargo, esta lectura no contempla las afirmaciones realizadas por el propio Heidegger, al decir que más originaria que la temporalidad del Dasein, es la temporalidad del ser.

5 Los términos alemanes Eigentlich y Uneigentlich pueden traducirse de distintas maneras, por ejemplo, como propio e impropio respectivamente, o como genuino y no genuino, auténtico e inauténtico. Aquí se elige emplear los términos autenticidad e inautenticidad para evitar la redundancia del texto.

6 La metodología que estructuró Heidegger para ST consistía en un examen del ser del hombre que habría de brindarle las herramientas para replantear la pregunta por el sentido del ser. En su examen, el filósofo se centra en los modos de ser auténtico e inauténtico, mas en su obra él deja abierta la posibilidad a considerar otros modos de ser. En el §12 menciona que el hombre vive, por así decir, en la autenticidad, la inautenticidad o la indiferenciación modal de ellas, sin embargo, Heidegger no ahonda en cómo podría pensarse esa 'indiferenciación modal'. 
manera de comprender y actuar en el mundo; ${ }^{7}$ la existencia inauténtica es una pérdida de sí mismo, el hombre en lugar de apropiarse de sí deja que el 'uno' decida por él. La existencia auténtica, por su parte, denota el modo de ser en el que el hombre comprende que él es posibilidad, que puede apropiarse y responsabilizarse de su existencia; en la autenticidad el hombre se resuelve, elige adueñarse genuinamente de las posibilidades que se le abren (Heidegger, 1997, § 56-60).

En los textos tardíos (como Tiempo y ser [2011]), Heidegger vuelve a retomar los términos Eigentlich y Uneigentlich, pero el sentido que se les otorga ya no refiere a la apropiación de nuestras posibilidades o a la ausencia de ellas, sino a que el hombre es el ente al que le es inherente comprender al ser, y para él lo más auténtico es apropiarse del sentido que se abre temporalmente en el acontecimiento. Si el hombre no fuera receptor del darse temporalmente el ser, no habría un desocultamiento del ser y "[e]l hombre no sería hombre" (Heidegger, 1998, p. 32; GA 14, p. 16).

El cambio respecto de la forma en la que Heidegger ataca la pregunta por el ser, así como la resignificación de los términos dificulta encontrar nexos entre los distintos periodos del pensamiento heideggeriano. Pero allende esta dificultad, en este breve espacio se busca generar una reflexión acerca de cómo podría comprenderse la existencia auténtica (que se esboza en ST) en la época de la técnica.

La creencia ciega en la técnica moderna corresponde al auge del pensamiento metafísico, al completo olvido del ser por lo ente; esta creencia adviene junto con otra que se ha enraizado en el hombre: la ilusión de que él domina y somete a su antojo lo ente. Discusiones contemporáneas acerca de problemáticas como v.gr. el calentamiento global, la aceleración social, la inteligencia artificial, etc. se desarrollan en torno a esta creencia, pues ellas critican o defienden el "dominio" del hombre sobre lo ente, así como el rol que los objetos de la técnica moderna han adquirido en la sociedad. El 'uno's (en el sentido de ST) de nuestra época es el apogeo del pensamiento metafísico al que arribamos con la ciencia y la técnica moderna, ellas han permeado la vida del hombre determinado su existencia. Sin embargo, ¿cómo podría concebirse la existencia auténtica en la época de la técnica?, es decir, ¿cómo podríamos pensar en una apropiación de nuestras posibilidades?, ¿puede concebirse la existencia auténtica, un modo que tomaría distancia de la técnica moderna, como el pensar genuino que Heidegger denomina serenidad?

La tarea a primera vista es sencilla, dicho muy brevemente, la época regida por la técnica moderna es la época en la que el hombre olvida y oculta por completo al ser, en la que el mundo parece ser reducido a entes que son manipulables, usados a voluntad por el hombre; en esta época creemos equívocamente que las máquinas

7 Me refiero aquí al término alemán Das Man, que se traduce como ‘uno' o 'se'. El 'uno' no es una persona determinada, sino que refiere a los sentidos instaurados y empleados social e históricamente, a las opiniones comunes, etc.

8 No se busca sugerir aquí que el decir del 'uno' corresponda solo a la creencia en la primacía del hombre sobre lo ente, sino que esta es una de las facetas que él adquiere contemporáneamente. 
son creadas para poner los entes a nuestra disposición (incluyendo el tiempo). ${ }^{9}$ En ella prima el pensar calculador y planificador que está solo a la espera de ciertos resultados productivos. Vista así la tarea, en la época de la técnica, el hombre que se cree a sí mismo dominador de lo ente existe inauténticamente, mientras que la existencia auténtica correspondería a la serenidad (Gelassenheit), a un pensar genuino que puede superar la metafísica. No obstante, ese tipo de respuesta es prematura, y podría llevar a creer erróneamente 1.) que la existencia auténtica e inauténtica no son modos entre los que oscila la existencia, sino que son términos con una connotación ética ${ }^{10} y$, que pensar genuinamente, es excluir de sí toda posibilidad de la dominación de la técnica moderna; 2.) que la serenidad sería el único rostro que podría adoptar la existencia auténtica en nuestra época; 3.) que el pensar genuino (la serenidad) es una oposición o una postura neutral respecto de la técnica. Si bien la autenticidad es una toma de distancia del 'uno', ella no involucra un rompimiento total con los sentidos establecidos socialmente, es decir, aún la existencia auténtica subsiste en el mundo del 'uno'. La autenticidad es el modo en el que el hombre deja ser sus posibilidades y se resuelve a elegir entre ellas. La existencia auténtica en la época de la técnica no abandona el mundo de sentido en el que se encuentra, ni lo mira de manera pasiva sin involucrarse con él. Y 4.) en tal lectura se estaría olvidando que una de las diferencias fundamentales entre los modos de la existencia corresponde a cómo en uno y otro se experimenta la temporalidad. Pero entonces, ¿cómo se ha de entender que la serenidad no es una aceptación, una oposición, ni una posición neutral respecto de la técnica?, ¿la serenidad no es entonces el alcanzar un estado que abandona de manera irreversible el pensamiento metafísico?

9 La crítica que realiza Heidegger al 'tiempo vulgar' —a las nociones tradicionales y metafísicas del tiempo— cuestiona, entre otras cosas, que la filosofía pregunte por el tiempo empleando la fórmula ¿qué es el tiempo?, pues ello pone en evidencia que muchas de las reflexiones sobre el tiempo (por ejemplo, en Aristóteles o Agustín) tratan al tiempo como si se tratase de un ente (Cf. Heidegger, 2004; GA:64). En las sociedades contemporáneas la primacía de la noción de tiempo vulgar es palpable, pues el tiempo es considerado un recurso que se agota a cada segundo, y, para 'usarlo' al máximo, vivimos en función del reloj y de distintas herramientas que nos ayuden a aprovechar y determinar cada instante.

10 En ST, Heidegger insiste en que, a pesar de los términos que emplea, su trabajo es ontológico y no ético; la inautenticidad no es un modo de ser inferior e incorrecto, ni la autenticidad uno superior. En el análisis que realiza Heidegger sobre la voz de la conciencia (Cf. Heidegger, 1997 , §57-58), ésta es distinguida como anterior a la ética, pues ella al hablarnos nos indica oportunidades perdidas, nos muestra que podíamos haber tomado un rumbo diferente; la conciencia no nos habla de lo bueno y lo malo, sino que demanda que prestemos atención a la posibilidad (por lo anterior es que tras escuchar a la voz de la conciencia, el hombre quiere tener conciencia, es decir, quiere notar las posibilidades que se le abren). La conciencia es anterior a la ética, juzgar una acción como buena o mala es posterior a escuchar la voz de la conciencia, a notar que había otros caminos que no elegimos. Años después de ST, en la Carta sobre el humanismo (2000), Heidegger insiste en que su obra no posee un contenido ético; en este texto Heidegger cuestiona que se interpretara que $S T$ tenía un contenido ético, cuando lo que buscaba plantear el filósofo de Friburgo era una ontología fundamental que sería anterior a cualquier discurso sobre ética. 


\section{Temporalidad de la existencia y temporalidad del ser}

Ahora sí entremos en el tema de manera más detallada. Para iniciar me remitiré primero a la Nueva refutación del tiempo de Jorge Luis Borges (1994). En dicho ensayo el escritor argentino intenta refutar la existencia del tiempo al cuestionar las nociones metafísicas tradicionales (en especial Berkley y Hume), a saber: 1.) el tiempo concebido como una sucesión infinita de instantes y que constituye el número del movimiento (se emplea para medir el movimiento; noción proveniente de Platón y Aristóteles y adoptada luego por la física), y 2.) la concepción del tiempo como estructura mental (idealismo temporal). ${ }^{11}$ Si bien el análisis borgiano no es el tema que aquí nos ocupa, me permito retomar la conclusión a la que llega el argentino:

Negar la sucesión temporal, negar el yo, negar el universo astronómico, son desesperaciones aparentes y consuelos secretos. Nuestro destino (a diferencia del infierno de Swedenborg y del infierno de la mitología tibetana) no es espantoso por irreal; es espantoso porque es irreversible y de hierro. El tiempo es la sustancia de que estoy hecho. El tiempo es un río que me arrebata, pero yo soy el río; es un tigre que me destroza, pero yo soy el tigre; es un fuego que me consume, pero yo soy el fuego (Borges, 1994, p. 114).

Pese a que Borges refuta el tiempo con gran elocuencia -ya sea retomando a Berkeley, Schopenhauer o Hume- y de manera, podría decirse, relativamente exitosa, la conclusión corre a contracorriente de los argumentos que ha presentado. Negar el tiempo es simplemente un consuelo secreto, porque él es nuestro destino y la sustancia de la que estamos hechos.

La licencia de retomar aquí a Borges se extiende a leer la conclusión en clave heideggeriana. Comencemos por la última parte del párrafo y separando algunas de las oraciones, es decir, "el tiempo es la sustancia de la que estoy hecho, yo soy el río, yo soy el tigre, yo soy el fuego" (Borges, 1994, p. 114). En ST, para emplear las palabras de Heidegger: "Como sentido del ser del ente que llamamos 'ser-ahí se muestra la temporalidad" (Heidegger, 1997, p. 27). La existencia posee un sentido temporal, el hombre no es solo un ente cuya vida trascurre en el tiempo, sino que el tiempo mismo es el contenido de su ser. Las modalidades del tiempo sido, presente, advenir determinan constantemente la existencia, es decir, el pasado y el futuro inciden en el presente y viceversa. Dicho de manera escueta, el pasado no es un suceso remoto, ni el futuro

11 Por una parte, las nociones que Borges cuestiona constituyen lo que Heidegger denomina la concepción vulgar de tiempo. Por otra parte, se debe aclarar que la noción ideal de tiempo no necesariamente niega la noción que afirma al tiempo como una sucesión de instantes o como número del movimiento. Aquí me tomo la libertad de distinguir dichas nociones de este modo para contrastar la idea del tiempo como mera herramienta y el tiempo como estructura mental. Borges se ocupa más que todo de poner en cuestión al idealismo temporal, pero algunas de sus reflexiones aplican también a la concepción del tiempo como medida del movimiento. 
solo algo que se espera, sino que pasado y futuro están llenos de significatividad e intervienen constantemente en el presente, aún en acciones que en apariencia son más simples y que no requieren de una elección. ${ }^{12}$

Pero, aunque el tiempo es inherente a la existencia, no siempre notamos que la temporalidad es el contenido de nuestro ser. La existencia inauténtica, al seguir los sentidos instaurados, cree que el tiempo es un algo que nos ayuda a medir el movimiento, un recurso que se agota a cada segundo y que sólo vivimos en el instante presente. ${ }^{13}$ La noción vulgar de tiempo se fortalece en la época de la técnica, ya que en ella se instiga al hombre a vivir sólo en el instante, a responder a las exigencias que le salen al paso día a día, sin siquiera contemplar que su existencia no está determinándose solo en función del presente, pues pasado y futuro también la constituyen. Por su parte, la existencia auténtica experimenta genuinamente la temporalidad, nota la confluencia de pasado, presente y futuro en la existencia. El hombre al comprender su finitud, al enfrentarse a la muerte, descubre que ella es la posibilidad más propia, inevitable e irrebasable que posee, la posibilidad de la clausura de la existencia. La comprensión del sentido ontológico de la muerte (como cierre de la existencia) genera, a la vez, que el hombre vea que las otras opciones que se le abren no son sino posibilidades entre las que puede elegir. El hacer frente a la muerte y el comprender su sentido ontológico abre la puerta a que el hombre se resuelva a apropiarse de su existencia y a elegir genuinamente. La existencia auténtica al resolverse a apropiarse de sí deja de ver el tiempo como una sucesión infinita de ahoras, y pasa a notar que su existencia definida por la posibilidad porvenir (futuro ${ }^{14}$ ) que es la muerte; no obstante, la resolución no solo abre la existencia al futuro, sino que presente y el pasado confluyen con él; realizar una elección genuina es elegir a partir del pasado (quien ya he sido) encaminándonos en una posibilidad (futuro/ advenir) que ya me determina. Visto así: "el tiempo es la sustancia de la que estoy hecho, yo soy el río, el tigre y el fuego" (Borges, 1994, 114). El sentido de mi ser es lo que he sido (pasado), las posibilidades en las que me encamino (futuro), y que constituyen quién soy. La temporalidad es propia del hombre.

Pero ahora veamos el complemento de la oración, a partir del segundo Heidegger, es decir,

12 V.gr. Cuando se tiene hambre y se busca algo de comer, esta acción se realiza empleando un tenedor y cuchillo para lograr saciar el hambre. El empleo de estas herramientas lo realizamos gracias a que nos enseñaron en el pasado, por un lado, que ese es el modo correcto de comer, y, por el otro,de lograr el objetivo esperado.

13 Desde la antigüedad el tiempo ha sido concebido como medida del movimiento y se habría empleado como una herramienta. Sin embargo, a diferencia de otras épocas, la actual no solo 'emplea' al tiempo para determinar las estaciones o el pasar de los días, sino que pretende poder emplearlo a gusto al querer controlar cada instante, la duración de cada proceso y acción (Cf. Rosa, 2016).

14 Heidegger privilegia el futuro (advenir) pues la muerte es la posibilidad más propia de la existencia, posibilidad que está siempre latente y la determina en cada instante. Dicho en otros términos, en tanto que el hombre es existencia (posibilidad) está siempre haciéndose a sí mismo en virtud del futuro, de un advenir que desemboca en la muerte. 
nuestro destino no es espantoso por irreal [...] es espantoso porque irreversible y de hierro. El tiempo es la sustancia de la que estoy hecho. El tiempo es un río que me arrebata, un tigre que me destroza, un fuego que me consume (Borges, 1994, p. 114).

Mientras que en la analítica existenciaria la temporalidad es el sentido del ser del hombre (es propio del hombre), la temporalidad tras la Kehre deja de depender del Dasein. Heidegger dirá: se da ser y se da tiempo (Cf. Heidegger, 2011). Dicho de otro modo, ser y tiempo emergen, acontecen, y su acontecer no es una donación del hombre (Ereignis). El ser emerge en un juego de ocultamiento y desocultamiento, sale a la presencia instaurando las distintas aperturas o épocas de la historia de la metafísica que se constituyen o se encuentran dominadas por esos modos de presenciarse el ser. Cada época de la historia de la metafísica está determinada, por retomar los términos de Raïner Schürman (1982), por una economía de la presencia, por un principio (o un desocultamiento) que funda y dirige, que produce un orden de inteligibilidad y que da coherencia a la cultura.

La época se instaura gracias a la donación de ser y tiempo que acaba constituyendo el destino del hombre porque determina las posibilidades de la existencia. Sin embargo, con las palabras se da ser, se da tiempo no se indica que el hombre sea un mero espectador pasivo, el acontecer del ser depende de una apropiación de él, de un oído atento que escuche su verdad, es decir, hay una co-pertenencia entre ser, tiempo y hombre. Así, el tiempo es la sustancia de la que estoy hecho, porque me determina, constituye el destino irreversible y de hierro de mi existencia, él es el río que me arrebata, el tigre que me destroza y el fuego que me consume. Ser y tiempo se dan instaurando la época que constituye el destino que me guía y me determina. El tiempo acontece, acaece sin originarse en mí, y, no obstante, es propio del hombre el corresponder al acontecer, el apropiarse del sentido que se ha presenciado temporalmente.

Leamos entonces a nuevamente la sentencia borgiana (con todos los problemas que ello pueda contener):

Nuestro destino [...] no es espantoso por irreal; es espantoso porque es irreversible y de hierro. El tiempo es la sustancia de que estoy hecho. El tiempo es un río que me arrebata, pero yo soy el río; es un tigre que me destroza, pero yo soy el tigre; es un fuego que me consume, pero yo soy el fuego (Borges, 1994, p. 114).

Las palabras de Borges permiten unir las dos versiones de la temporalidad heideggeriana: el tiempo no es un producto del hombre, sino que el tiempo acontece, se da; pero, a la vez, yo me apropio de la donación tiempo (y ser) al punto que experimento el tiempo como propio y como el sentido de mi ser. Yo no creo ser y tiempo, no instauro épocas, sino que correspondo a los desocultamientos del ser que las han instaurado; en la apropiación del acontecer el tiempo acaba siendo la sustancia de la que estoy hecho, y en la que yo mismo me convierto en el río, el tigre y el fuego, en la que experimento el 
tiempo como el sentido de mi ser. Unir las dos nociones de temporalidad implicaría que los modos en los que experimentamos (nos apropiamos) el tiempo varían dependiendo de las aperturas de ser (o de las épocas de la metafísica), y genera que la existencia auténtica adquiera distintas formas dependiendo de las donaciones de ser; por lo cual se debe preguntar cómo puede pensarse la existencia auténtica en la época de la técnica.

La unión de las dos nociones de temporalidad puede quedar un poco más clara si se traen a colación análisis como los que realizan Harmut Rosa (2009; 2016) o Paul Virilio (2000; 2006) al examinar las maneras en las que contemporáneamente experimentamos el tiempo. La época adviene y, junto con una aceleración social, afirman que ella nos impone vivir de modo más rápido, a creer que una vida lograda consiste en movernos de manera más veloz entre espacios, entre modos de vida, e incluso, de ser posible, vivir diferentes modos de vida en una sola (lo cual acaba equivaliendo a una promesa de eternidad). ${ }^{15}$ Rosa (2016) lo expone de un modo mucho más adecuado: en otras épocas las personas elegían un oficio, eran contratados en una empresa determinada y se jubilaban en la misma, viajaban pocas veces a otros países, y muchas menos, si es que alguna, a otro continente. Ahora, ello no es suficiente, sino que la época apremia al hombre a viajar, a aprender idiomas, a vivir y aprender de distintas culturas, el espacio cambia y se reduce de tal modo que mantenerse quieto es inexcusable. Ahora bien, el análisis que realizan los teóricos de la aceleración no se limitan a mostrar cómo la técnica moderna adviene con modos de vida más acelerados, sino también a cómo el modo en el que experimentamos el tiempo mismo se trastoca; el hombre de la modernidad tardía se vuelve como el motociclista de Kundera en La lentitud:

[E]l hombre encorvado encima de su moto no puede concentrarse sino en el instante presente de su vuelo; se aferra a un fragmento de tiempo desgajado del pasado y del porvenir; ha sido arrancado a la continuidad del tiempo; está fuera del tiempo; dicho de otra manera, está en estado de éxtasis; en este estado no sabe nada de su edad, nada de su mujer, nada de sus hijos, nada de sus preocupaciones, y, por lo tanto, no tiene miedo, porque la fuente del miedo está en el porvenir, y el que se libera del porvenir no tiene nada que temer.

La velocidad es la forma de éxtasis que la revolución técnica ha brindado al hombre. [...] Todo cambia cuando el hombre delega la facultad de ser veloz a una máquina: a partir de entonces, su propio cuerpo queda fuera del juego y se

15 Hans Blumemberg en Tiempo del mundo y Tiempo de la vida (2007) plantea que con la secularización el mundo sería visto como eterno en tanto que indiferente a la muerte humana, mientras que el tiempo de la vida es una secuencia de ahoras que se agota a cada segundo. Rosa (2016), siguiendo a Blumemberg plantea que la aceleración que adviene con la técnica es un intento por cerrar la brecha entre la finitud y la infinitud, al punto que se cree que al incrementar la velocidad es posible vivir multiplicidad de vidas e incluso pasar por todas las posibilidades que el mundo tiene para ofrecer. Sin embargo, es evidente que la promesa es vacía, a más velocidad, más posibilidades se crean y la porción que logramos recorrer continúa siendo ínfima. 
entrega a una velocidad que es incorporal, inmaterial, pura velocidad, velocidad en sí misma, velocidad éxtasis (Kundera, 2011, p. 4).

El hombre en la modernidad tardía se aferra a su moto igual que el hombre encorvado de Kundera, es arrancando de la continuidad del tiempo. La época de la técnica es no solo la época en la que se delega la velocidad a una máquina, ella es el auge de la metafísica, y por lo mismo, el auge de la creencia de que el tiempo es un ente que puede ser manipulado y que se agota a cada instante; paradójicamente, el hombre al estar tan enfocado en el paso del tiempo se desprende del tiempo mismo, pierde su pasado y su futuro, y se entrega a la incorporeidad e inmaterialidad de la velocidad, a la inautenticidad para la cual solo existe el ahora. El motociclista de Kundera no difiere de la existencia inauténtica que cree que el tiempo es una herramienta que empleamos para medir el movimiento, o que cree que solo existe el instante presente, mientras que el pasado es un ahora que dejó de ser, y el futuro un ahora que no llega.

\section{Técnica y época de la técnica}

Para explicar cómo el hombre se apropia del Ereignis de manera más adecuada, me referiré aquí primero a la técnica en general. En La pregunta por la técnica, Heidegger (2007d) retoma la teoría de las cuatro causas de Aristóteles, es decir, materia, forma, causa eficiente y causa final. Contemporáneamente, la materia, la forma y la finalidad no son concebidas como causas, sino que nuestra noción de causalidad se restringe a la causa eficiente, entendida esta como el resultado de la acción de un agente, o la imposición de una forma a la materia. Cabe recordar que Aristóteles (2014) no concebía la causa eficiente de la misma manera, sino como un poner en movimiento (el principio del movimiento). Heidegger propone que la manera justa de comprender la teoría de las cuatro causas es viéndolas relacionadas entre sí.

Según Giorgio Vasari, Miguel Ángel acerca de su escultura La piedad, dijo:

En cada bloque de marmol veo una estatua tan claramente como si estuviese frente a mi formada y perfecta en actitud y acción. Sólo tengo que eliminar las paredes de piedra que la aprisionan, y revelar a otros ojos lo que los míos ya han visto (Vasari, 1998, p. 85).

La materia no es algo simplemente pasivo para un escultor, ella sugiere la forma, y el trabajo del artista, no es imponer su voluntad sobre el mármol, sino revelar a otros la aparición que tiene ante sus ojos, su trabajo es puramente contemplativo. Dicho de otra manera, la forma, la materia y la finalidad, inducen al escultor quien debe ayudarlas a poner en libertad a la obra de arte. 
Las cuatro causas son modos de un dar-lugar-a, y "todo dar-lugar-a que algo (cualquiera que sea) desde lo no-presente a la presencia, es $\pi$ oínбıs, es pro-ducir"16 (Heidegger, 2007d, p. 119; GA 7: 12). Las cuatro causas no son responsables de la creación o del venir a la presencia de nada, sino que ellas son un dejar ser libres a las cosas. El rol del hombre es en apariencia pasivo, en tanto que él es un asistente al develamiento del ser. Pero este dejar ser a las cosas tiene un sentido activo (que no implica un imponer). Descubrir -similar a develar o desocultar- no significa crear ex nihilo lo ente al modo de un dios; quien descubre algo destapa lo que está cubierto, pero no impone su voluntad, ni crea de la nada, pues si fuera así, tendríamos que considerar a Cristóbal Colón como el dios del continente americano. El dejar que venga a la presencia lo que todavía no es presente, es un descubrimiento, el conteniente americano y la escultura ya son, pero aun así nadie se atrevería a decir que Miguel Ángel o Colón se mantuvieron inactivos, pues en ese caso no tendríamos acceso a lo que el ser manifestó a cada uno. Producir una obra, no es dejar ser a la obra como se creería a partir de la técnica moderna, sino que dejar ser a la obra es producirla, ayudarla a salir a la luz.

El rol de asistente del ser por parte del hombre se hace claro si se recuerda que en su texto Heidegger considera que la physis es también una poesis, e incluso es la poesis por excelencia, porque lo que viene a la presencia no surge de una imposición, sino que surge por sí misma y sin ayuda alguna. Para retomar uno de los ejemplos de Heidegger, el agricultor no crea las flores, sino que las deja ser, las nutre. En el caso de las cosas producidas por la mano del hombre ellas no vienen a la presencia si no es por la contemplación que descubre aquello que permanece escondido. El artesano es aquí causa eficiente, pero no somete al mármol, sino que se pone a su servicio.

La técnica es entonces distinta de la época de la técnica, la primera es uno de los modos en los que el ser se devela, la última es el establecimiento de la técnica moderna, con todo lo que ella implica, como principio de inteligibilidad de las cosas y como época en la que la contemplación se pierde, y el hombre cree ejercer su voluntad sobre la materia interesándose solamente por la finalidad.

Aquí no pretendo resumir ni retomar todos los puntos del texto heideggeriano. Pero sí me interesa señalar la poiesis como un modo del desocultamiento del ser. Aunque se debe indicar que el paso que va de la techné griega a la técnica moderna es el paso de un modo de atender al desocultamiento del ser a otro. ${ }^{17}$ En la primera las cuatro causas se entendían como una unidad que da-lugar-a, como un producir que contribuye al emerger del ser, mientras que en la época de la técnica, parafraseando a Heidegger, es más patente el olvido del ser y el hombre se concibe a sí mismo como sujeto que ejerce por completo su voluntad sobre lo ente, sin notar que él no dictamina lo que son los

16 Heidegger traduciendo El banquete de Platón (205b s.).

17 Para comprender la discusión sobre la técnica en Heidegger se recomiendan los textos de Garrido (2018) y Miranda (2017). 
entes, ni cómo son ellos para nosotros. El hombre no controla el desocultamiento, sino que el ser posee una prioridad respecto de la subjetividad humana.

Así, la pregunta por la técnica - sea la técnica en general o por la época de la técnica- es la pregunta por el modo en el que correspondemos al desocultamiento del ser y por la libertad humana (Cf. Heidegger, 2007a). Si bien el desocultamiento del ser constituye para Heidegger el destino del hombre, por destino no debe entenderse una erradicación de la libertad humana y un fatalismo determinista que propone un seguimiento ciego a la tradición, como lo interpretó Leo Strauss (2014).

Para referirse al destino, al menos en La pregunta por la técnica, Heidegger juega con los términos Schicken (enviar), das Geschick (destino) y Geschichte (historia). La historia es un envío (el acontecimiento del develamiento del ser) y el destino lo que es enviado, es decir, el destino es nuestra comprensión del ser. La libertad, en este periodo de pensamiento heideggeriano, posee dos sentidos (como se explica en La esencia de la verdad (2007a) o en La esencia de la libertad humana. Introducción a la filosofía (1982), por un lado, un sentido ontológico, en el que ella es la condición para el develamiento del ser, es decir, la libertad permite que el acontecer de ser y tiempo se den. Por otro lado, un sentido 'humano' que no refiere a una propiedad o una capacidad del hombre de actuar acorde a su voluntad y sin coerción alguna, o sin referencia alguna al mundo, sino que ser libre es ser-en-el-mundo, es estar inmerso en los desocultamiento del ser, es comprender el ser y estar comprometido con él. El hombre posee un destino que determina su libertad, pero éste (el destino) no es más que el fondo sobre el cual puede el hombre ser libre, elegir.

Esta noción de libertad se encontraba ya en germen en ST; en esta obra la libertad es distinguida como un dejar-ser a las cosas, un permitir que lo ente se nos muestre en sus posibilidades y conformarse a ellas; no somos libres solo porque elegimos entre opciones, ${ }^{18}$ pues ellas pueden estar ya establecidas previamente por el 'uno', somos libres porque al dejar-ser lo ente permitimos que él se nos muestre en sus posibilidades (allende los dictámenes del 'uno') y, por lo mismo, elegimos genuinamente. Si bien, en los textos de 1930, Heidegger varía un poco su noción de libertad ${ }^{19}$ (al considerarla condición de posibilidad de la verdad y ya no como la condición de la elección auténtica), la variación es mínima, y puede verse como un paso atrás que conduce a un terreno más originario, pues continúa estando ligada a una apropiación de las posibilidades que se abren para nosotros desde el ser. Escuchar los envíos del ser es corresponder al sentido, dejar que él acontezca para nosotros en orden de elegir.

Por ejemplo, ¿puede el hombre dudar de que el tiempo es la herramienta que mide el movimiento o de que tal se compone de una sucesión infinita de instantes, de que el

18 Un condenado a muerte, v.gr., puede elegir morir en la horca, la silla eléctrica y la inyección letal, y, sin embargo, no tiene una opción diferente de aquellas que otros han dictaminado para él.

19 En especial porque el hombre perdió el lugar central que tenía respecto de la pregunta por el sentido del ser. 
minuto en el que leí el anterior párrafo constituye respecto del instante presente, el pasado?, ¿no son los minutos pasados instantes que no volverán y el futuro los instantes que aún no han llegado, y los cuales puedo datar por medio del reloj? ¿El burócrata que espera que el reloj dé las 5 para acabar su jornada laboral no está en espera de un minuto determinado, y no es así esclavo de la verdad que marca el reloj? y ¿no es esa comprensión del tiempo la manera en la que este se había desocultado para la tradición metafísica? Sólo al dejar-ser al tiempo puede el burócrata notar que el minutero no es la única posibilidad que se abre con el futuro, lo que importa no es el instante por venir sino el sentido que con él adviene, la posibilidad de descansar, de realizar planes hechos con anterioridad, o al menos de llegar a casa. Pero mientras prime la idea de que el futuro es solo un instante, el burócrata se restringe al minutero y acaba como el motociclista desgajado del tiempo.

Sin embargo, considerar que el hombre corresponde solo a lo que el ser quiere mostrarle nos hace cuestionar por qué la tradición metafísica no logró poner en libertad al tiempo. La existencia del burócrata, la del griego y la del medieval también están determinadas por la relación entre ser y tiempo, solo que para ellos -y tal vez hoy más que nunca- está oculto que el tiempo inhiere a la existencia. La dificultad de que antes no hubiera podido mostrarse la temporalidad de la existencia y el Ereignis, puede deberse al modo en el que la tradición formuló la pregunta por el tiempo. Preguntar ¿qué es el tiempo? es concebir al tiempo como un fenómeno o un ente, como una herramienta que puede ser puesta a nuestra disposición, o como una estructura mental que nos permite notar el movimiento. Dicho de otra manera, la formulación de la pregunta por el tiempo con la estructura ¿qué es...? determinó el modo en el que ella fue atacada, ya que se concibía como algo en lo que trascurre la existencia y no como propio. Puesta así la pregunta, la tradición no tenía la posibilidad de mostrar las facetas más originarias del tiempo, a saber: la temporalidad de la existencia y el Ereignis. Por su parte, la pregunta por el tiempo en la filosofía heideggeriana no pregunta qué es el tiempo -como si se preguntara por un ente-, la empresa heideggeriana es más bien un intento por sacar a relucir la co-pertenencia entre ser y tiempo. Esta empresa que pretende mostrar el camino erróneo en el que se había instalado la metafísica al entificar ser y ente, y en la que, al revelar la unión entre ambos, entre el sentido y el tiempo, exhibe la inherencia del tiempo a la existencia y cómo ser y tiempo se dan instaurando época.

Antes de proseguir se debe aclarar que lo anterior no ocurre del mismo modo para con todos los desocultamientos. El auto-movil o el teléfono móvil dependen de desocultamientos anteriores, la mecánica, etc. El caso del tiempo es distinto por su carácter ontológico, porque constituye una estructura de la existencia, y, no obstante, según Heidegger, no sería sino hasta un ocultamiento máximo del ser -como el de nuestra época- que se descubre el carácter ontológico del tiempo y su co-pertenencia con el ser. 


\section{Existencia auténtica en la época de la técnica}

Preguntar por la época no es solo preguntar por cómo se generan las aperturas epocales, sino, más importante aún, por cómo responde el hombre a ellas, y cómo se atiende al desocultamiento, ya sea olvidando el ser o por la creencia de la dominación de lo ente (el 'uno' en la época de la técnica), o de una manera más auténtica. La serenidad ${ }^{20}$ es un modo de ejercer esa libertad -y habría que pensar si es el único o no (Cf. Heidegger, 1994). Gracias a ella se descubre algo que permanecería escondido si no fuese por el producir. Richard Rojcewicz (2006) plantea que la contemplación es entonces un ejercicio semi-creativo, en ella se descubre la esencia de una posibilidad que ya existe pero que surge solo luego de su cuidadosa consideración, lo revela, pero dicha revelación requiere de la cooperación del hombre, de su ayuda y de su producir.

La serenidad es, en términos de ST, un dejar-ser a las cosas que nos permite apropiarnos del darse el ser, es "dejar ser algo «a la mano tal como a la sazón es y fundamentalmente en un sentido ontológico" (Heidegger, 1997, p. 99). La conformidad (el dejar-ser a lo ente) significa que el hombre no impone o produce el ser de las cosas, sino que permite que los entes le hagan frente en su ser, es un corresponder al ser. El ejercicio de Miguel Ángel como escultor era dejar-ser al mármol, dejar que él mismo se le develara su ser, y la conformidad no fue sino un corresponder al develamiento produciendo la obra de arte.

Aquí se ha llegado al corazón de lo que me interesa plantear aquí, el pensar contemplativo (la serenidad) es una actitud ante las cosas y un modo de ser en el mundo, un ejercicio de la libertad. La serenidad no es una manera pasiva, inactiva, alejada del mundo. No es un volverse ecologista o budista, ni mucho menos un volver a un modo de vida pasado que no requería de la técnica moderna. Por el contrario, es un compromiso con el desocultamiento del ser y, si el ser actualmente se desoculta por medio de la técnica, debe haber una cierta apropiación de dicho desocultamiento. No obstante, puede ser evidente que tal compromiso o apropiación no equivalen aquí a un seguimiento ciego.

Heidegger afirma que hay que decir "sí y no a los objetos técnicos" (Heidegger, 1994, p. 76). La serenidad no es una oposición, ni una postura neutral. El dictador y el revolucionario se necesitan mutuamente. Quien se opone a los objetos técnicos -no a la técnica como uno de los modos de desocultamiento del ser- reconoce su poderío y determina su vida en relación con ellos, así sea de manera negativa al rehusarse v.gr., a tener un teléfono móvil o un correo electrónico alegando el dominio que ellos pueden ejercer sobre su vida. Pero la oposición, como en el caso de la negación del tiempo borgiana, es solo un consuelo secreto y no una distancia con el pensar calculador que

20 El término alemán Gelassenheit se traduce por lo general como serenidad, sin embargo, algunos autores, en especial norteamericanos, emplean el término contemplación. 
prima en la época de la técnica. Necesitamos el teléfono móvil y el correo, pero debemos aprender a distanciarnos de ellos, dejar en libertad su sentido y en ese punto podemos decir sí y no a la técnica. ${ }^{21}$

Pero, la serenidad tampoco es una actitud neutral, porque ella es contemplación que requiere de un compromiso con el ser, mientras que la neutralidad que algunos persiguen con respecto a la técnica es más bien neutralidad respecto de lo que se dice -es decir, neutralidad con respecto al decir del Das Man- de lo ente. Dicho de otro modo, quien es neutral respecto de la técnica moderna no piensa de modo contemplativo, sino que se mantiene al margen del acontecer en espera de que otros determinen si hay que decir sí o no.

La serenidad, aunque el término -al menos en español- parece corresponder a una actitud puramente pasiva, es una contemplación, pero en el sentido de la poiesis, es un atender al ser y ver lo que este revela. Decir sí y no a la técnica es ver el mundo ya no como una serie de cosas disponibles, calculables y desechables, sino dejar que ellas se muestren en su ser, es estar atentos al sentido que ellas abren. Con la serenidad, los objetos de la técnica pierden su poderío y esta pasa a ser relativa; gracias a ella se abandona, además, la creencia de que el hombre ejerce completo dominio sobre lo ente, cuando en realidad depende de algo que no es el hombre. Heidegger afirma que con la serenidad "[d]ejamos entrar a los objetos técnicos en nuestro mundo cotidiano y, al mismo tiempo, los mantenemos fuera, o sea, los dejamos descansar en sí mismos como cosas que no son algo absoluto, sino que dependen ellas mismas de algo superior" (Heidegger, 1994, p. 64). La serenidad no es un escape del mundo y de las cosas, sino más bien una actitud distinta respecto de lo ente, es dejar de ver a las cosas desde un pensar calculador y permitirles que ellas se nos muestren en su ser.

En Serenidad, Heidegger (1994) define la serenidad como un volver a lo autóctono. La autoctonía es un enraizamiento en el hogar, en este caso en el ser. El pensar calculador y planificador que adviene junto con la técnica moderna, al olvidar al ser por lo ente, nos destierra de nuestro hogar, nos impide estar en el lugar que nos es más propio (el corresponder al ser); con el pensar calculador el mundo deviene una serie de entes dispuestos para nosotros, pero respecto de los cuales no comprendemos su ser, ni nos interesa llegar a comprenderlo. Un pensar sereno debería entonces generar prácticas más genuinas o por lo menos modos más libres de actuar, y no una resignación a la imposición impropia de la voluntad sobre lo ente. Pero, si el anterior es un modo adecuado de comprender la serenidad, y si ella no constituye pasividad respecto del acontecer, ¿cómo puede actuar un pensar sereno?, ¿cómo puede corresponder y

21 El ejemplo más claro es tal vez cuando una persona busca trabajo. Si él se opone a tener un teléfono móvil y un correo electrónico, las posibilidades de encontrar trabajo disminuyen exponencialmente. En ese proceso oponerse a los objetos de la técnica moderna no logra ni reducir el impacto de la recepción de estas herramientas, ni ayuda genuinamente a la consecución del objetivo propuesto. Si lo que se busca es poner distancia, debe verse el correo electrónico como lo que es, la posibilidad de recibir correos importantes rápidamente y no como una herramienta que debe revisarse cada minuto del día. 
responder al acontecimiento? En política, por ejemplo, ¿cómo acaecería un actuar que produzca en el sentido de la poiesis? y ¿qué ocurre con otro tipo de acontecimientos ${ }^{22}$ como guerras, accidentes automovilísticos, enfermedades, el amor, la muerte, etc.? Si se da razón a los diagnósticos de los teóricos de la aceleración, si hay un aumento en la velocidad que permea el mundo, ¿el pensar sereno no debería también corresponder a ese aumento de la velocidad del acontecer?

\section{Conclusiones}

En este breve artículo se intentan unir las nociones de tiempo heideggerianas, y se trabaja con la hipótesis de que dicha unión está ya insinuada en ST. Se recordará que en la introducción de tal obra se anticipa que más originaria que la temporalidad del Dasein es la temporalidad del ser, y por lo mismo, la temporalidad extática y el Ereignis podrían considerarse nociones que son complementarias. Esta hipótesis contradice la creencia de que el joven Heidegger propone un idealismo temporal (Cf. Blattner, 1999) y se encierra en el antropocentrismo. En ese mismo sentido, se debe considerar que la noción de destino que se esboza en ST puede ayudar a comprender cómo podría darse una unión tal, pues ella permite pensar cómo el hombre posee un destino histórico (Cf. Heidegger, 1997, pp. 406-417), pero ello no mella la experiencia individual que tiene del tiempo.

La búsqueda por conectar la temporalidad del ser y la del hombre adquiere hoy día un rol particular, ya que implica comprender cómo la época determina las maneras en las que experimentamos el tiempo propio. Sin embargo, lo anterior implica que debe pensarse detenidamente los efectos que puede tener la época de la técnica en las modalidades de la existencia. El análisis existenciario que realiza el joven Heidegger nunca tuvo el interés de ser exhaustivo, y, si en efecto, él ya pensaba la temporalidad del ser como más originaria que la del hombre, entonces la época que se establece gracias al acontecimiento debe influir en las modalidades de la existencia al punto que puede generar nuevas exigencias, nuevas maneras en las que la existencia auténtica experimenta las modalidades del tiempo, y las formas en las que ocurre una apropiación de las posibilidades que se abren en el mundo.

La serenidad parece la exigencia que la época de la técnica tiene para el hombre, y el requisito para la existencia auténtica. Ella conlleva una distancia con las cosas y un dejar ser a las cosas que posibilita la libertad y la elección genuina. La serenidad no es solo un modo de explorar el mundo o acercarse de manera más libre a él, si ella es uno de los rostros que adquiere la existencia auténtica en la época de la técnica,

22 Tomo hechos que ocurren como acontecimientos porque ellos al surgir pueden modificar el sentido de la cotidianidad. Claude Romano en L'événement et le monde (1998), por ejemplo, concibe el amor, la muerte, la enfermedad, etc., como acontecimientos de la existencia. 
debe implicar otra manera de experimentar el tiempo mismo -tanto el tiempo propio, ${ }^{23}$ como la temporalidad del Ereignis. Pero sí es legítimo plantear que la serenidad es un modo de la existencia auténtica, un pensar sereno no es el arribo a estado superior que simplemente abandona de forma irrevocable la metafísica (y con ella a la técnica) y en el que solo atendemos al acontecer del ser, es también un oscilar entre la atención a lo develado y al ocultamiento. No hay un abandono, al menos a partir de la serenidad del pensamiento metafísico; la existencia continúa oscilando entre el acontecer del ser y el 'uno' (Das Man) de la técnica.

Si la serenidad es un modo de la existencia auténtica que atiende al acontecimiento, el producir (o el actuar) que adviene junto con ella implica una experimentación del presente, pasado y futuro, una proyección de las posibilidades que se abren que contemple a la vez el pasado para actuar en el presente y corresponder al acontecer, y tal vez dicha correspondencia ocurra también a la velocidad que exige la época, ya sea para decir sí o no a la técnica, para evitar volverse parte del aparataje técnico, o incluso para responder a otros acontecimientos como el amor o la guerra. El problema de dar ejemplos concretos de un actuar tal24 puede deberse a que todavía hay que reflexionar más a fondo en cómo y qué constituiría la serenidad, aunque tal vez el problema sea resultado de la época que todavía no la ha revelado genuinamente. Por ahora esta pregunta solo la puede responder la persona serena, y, sin embargo, aquí se intentó dar pistas acerca de lo que podría ser la serenidad. Lo que sí es claro en este punto es que la serenidad no es una forma de actuar que se pueda aprender y repetir como si fuese un hábito, sino que simplemente se da.

\section{Referencias}

Aristóteles (2014). Metafísica. Madrid: Gredos.

Blattner, W. (1999). Heidegger's temporal idealism. Washingtond. D. C.: Cambridge University Press. https://doi.org/10.1017/CBO9781139173155

Blumemberg, H. (2007). Tiempo del mundo y Tiempo de la vida. Madrid: Pretextos

Borges, J. L. (1994). Otras inquisiciones. Barcelona: Seix Barral.

Dastur, F. (1999). Heidegger and the question of time. Toronto: Humanity Books.

Gadamer, H. (2007). Verdad y Método. Salamanca: Ediciones Sígueme.

Garrido, A. (2018). Heidegger y Derrida. Sobre la cuestión de la ciencia y ténica. Madrid: Editorial Dykinson. https://doi.org/10.2307/j.ctv9zch64

23 El sido, el advenir y el presente que confluyen en la existencia.

24 Heidegger emplea ejemplos de arte. Sin embargo, creo que la serenidad debe pensarse como un producir más allá de la obra de arte. 
Han, B. (2012). Muerte y Alteridad. Barcelona: Editorial Herder.

Heidegger, M. (1983). Gesamtausgabe 29-30. Die Grundbegriffe der Metaphysik. Welt Endlichkeit - Einsamkeit. Frankfurt: Vittorio Klostermann

Heidegger, M. (1989). Gesamtausgabe. 64. Der Begriff der Zeit. Frankfurt: Vittorio Klostermann. Heidegger, M. (1994). Serenidad. Barcelona: Ediciones Serval.

Heidegger, M. (1997). Ser y tiempo. Buenos Aires: Fondo de Cultura Económica.

Heidegger, M. (1999). El concepto de tiempo. Madrid: Trotta

Heidegger, M. (2000). Carta sobre el humanismo. Madrid: Editorial Alianza.

Heidegger, M. (2005). The Esscence of human freedom: An introduction to philosophy. Bloomsbury Publications.

Heidegger, M (2007a), De la esencia de la verdad. Barcelona. Herder

Heidegger, M. (2007b). Los conceptos fundamentales de la metafísica. Mundo, finitud y soledad. Madrid: Alianza Editorial.

Heidegger, M. (2007c). Hitos. Madrid: Alianza Editorial.

Heidegger, M. (2007d). La pregunta por la técnica. Barcelona: Ediciones Folio.

Heidegger, M. (2011). Tiempo y ser. Madrid: Technos.

Kundera, M. (2011). La lentitud. Barcelona: Tusquets Editores.

Miranda, A. L. (2017). Técnica y ser en Heidegger. Salamanca: Ediciones Universidad de Salamanca. https://doi.org/10.2307/j.ctt201mp6v

Rojcewicz, R. (2006). The Gods and technology. A reading of Heidegger. New York: State University of New York Press.

Romano, C. (1998). L'événement et le monde. Paris: Presses Universitaires de France.

Rosa, H. (2008). High speed society: social acceleration, power, and modernity. Pensilvania: The Pensilvania State University Press.

Rosa, H. (2016). Alienación y Aceleración. Buenos Aires: Katz Editores. https://doi.org/10.2307/j. ctvndv5zf

Schürman, R. (1982). Le principe d'anarchie. Heidegger et la question de l'agir. Paris: Diaphanes. Vasari, (1998). La vida de Miguel Angel. Madrid: Visor Libros.

Virilio, P. (2000). From modernism to hypermodernism and beyond. New York: Sage Publications. https://doi.org/10.4135/9781446218242.n3

Virilio, P. (2006). Speed and politics. Cambridge, Mass: MIT press. 